\title{
THE APPLICATION OF DYNAMIC BAYESIAN NETWORK TO RELIABILITY ASSESSMENT OF EMU TRACTION SYSTEM
}

\section{ZASTOSOWANIE DYNAMICZNYCH SIECI BAYESOWSKICH DO OCENY NIEZAWODNOŚCI ELEKTRYCZNEGO SYSTEMU TRAKCYJNEGO}

\begin{abstract}
The article introduces a novel application of a Dynamic Bayesian Network (DBN) in the reliability assessment with regard to the traction system of Electric Multiple Units (EMU), which focus on modeling approach to DBN construction. As a result of high complexity and growing interdependencies, it is increasingly vulnerable to the failure of components. Although many studies on the use of BN for estimating the system reliability have been conducted, there is a lack of effective modeling power regarding current tools in depicting both functional and temporal dependencies between components. In this paper, a new modeling approach to DBN generation is submitted, which can be applied to the system made up of certain components and different types of flows propagating through them. The Component-based CPT (Conditional Probability Table) and Time-dependent CPT are used to describe functional dependencies and temporal dependencies respectively. As the complexity of the system cannot be modeled in a tractable way as a DBN, a Breadth-First-Search (BFS) algorithm is introduced for the construction of the DBN model in an automated manner. With the application of the proposed DBN-based approach, the reliability of the traction system can be evaluated at any given time, which is of great significance to determine the plan of maintenance in an effort to ensure the system safety.
\end{abstract}

Keywords: DBN; traction system; reliability assessment; breadth-first-search algorithm.

\begin{abstract}
W artykule omówiono nowatorskie zastosowanie dynamicznej sieci bayesowskiej (DBN) do oceny niezawodności elektrycznego systemu trakcyjnego ze szczególnym uwzględnieniem metod modelowania DBN. W zwiazku z rosnaca złożonością elektrycznych systemów trakcyjnych oraz wynikająca z niej coraz większa ilościq wspótzależności między komponentami, systemy te narażone sa coraz częściej na awarie części składowych. Chociaż istnieje wiele badań dotyczących oceny niezawodności systemów trakcyjnych, stosowane obecnie narzędzia nie maja odpowiedniej mocy modelowania koniecznej do opisu zależności funkcjonalnych i czasowych pomiędzy częściami składowymi. W niniejszej pracy zaproponowano nowa metodę modelowania generowania DBN, która można stosować w odniesieniu do systemów składających się z pewnych określonych komponentów oraz różnych typów rozchodzacych się przez nie przepływów. Zależności funkcjonalne i czasowe opisano, odpowiednio, za pomoca tablicy komponentowych prawdopodobieństw warunkowych (Component-based Conditional Probability Table, CPT) oraz tablicy czasowo-zależnych prawdopodobieństw warunkowych. Ponieważ złożoność systemu nie pozwala na zamodelowanie go w prosty sposób jako DBN, do automatycznej budowy modelu DBN wykorzystano algorytm przeszukiwania wszerz (Breadth-First-Search). Oceny niezawodności systemu trakcyjnego z wykorzystaniem proponowanej metody opartej na DBN można dokonywać w dowolnym czasie, co ma ogromne znaczenie przy planowaniu konserwacji w celu zapewnienia bezpieczeństwa systemu.
\end{abstract}

Stowa kluczowe: dynamiczna sieć bayesowska, system trakcyjny, ocena niezawodności, algorytm przeszukiwania wszerz.

\section{Introduction}

In recent years, a new era has seen the development of high-speed railway in China. By the end of 2012, China has boasted the coverage of about 9,356-km-high-speed railway[11]. The Beijing-Shanghai High-speed Railway which began to operate in July, 2011 has further pushed China towards super-high-speed trains with an operating speed of $380 \mathrm{~km} / \mathrm{h}$ [20]. During the 13th five-year plan, the high-speed railway is supposed to increase to $30,000 \mathrm{~km}$, covering more than $80 \%$ of big cities. This widespread coverage has definitely rendered the reliability of EMUs a top priority. Nowadays, EMUs are generally ascribed to the extreme complexity and interdependencies as a result of the systematic use of new technologies (such as artificial intelligence, information/communication technologies, or communication networks). Failures of EMUs could cause a catastrophic accident, for example, the Wenzhou High-speed train crash on July 23, 2011. To sum up, the extreme reliability, the most critical of EMUs regarding the traction system, can never be underestimated.

Over the past decade, the need to conduct an analysis of systematic reliability and safety assessment with respect to EMUs has long been recognized. In an effort to avoid economic losses and heavy casualties arising from safety violations, a large number of studies have been conducted to combine risk-based reliability analysis into safety control of EMUs. For example, Hanmin Lee, EuijinJoung, et al [18] built the management system in PDM (Product Data management) for failure history data to analyze the reliability of advanced EMU. Joung, E.[14], on the basis of the referenced RAMS standards, presented a system of reliability prediction and relevant demonstration procedure 
to apply it to the advanced EMU. As for the traction system, SeoS I, Park C S, Choi S H, et al. $[25,26]$ offered a procedure that can be utilized to assess and manage in a practical manner the reliability regarding the prototype system of train traction. With the application of reliability block diagram and failure mode effect, an analysis of reliability was carried out after the electric traction system is classified into subsystems. Chateauneuf Aet al. [8] put forward a methodology with the characteristic of consistency reliability to conduct an analysis of traction equipments subjected to fatigue, corrosion, and imperfect maintenance operations with a view to improving their inspection based on a balanced cost and reliability. For the purpose of meeting the challenge that different functions of sub-systems are likely to be activated in different contexts, Wang S, Ji Y, Dong W.[30] devised a new model of reliability analysis which is based on stochastic automata for the traction system of high-speed train. With the theory of stress-intensity distribution interference in mind, and the use of the mode of advanced first order and second moment, Li Cet al. [19] formulated a reliability model to estimate the reliability of an EMU traction system.

An increasing number of recent studies have emphasized on the estimate of reliability with regard to EMUs with the use of Bayesian networks $(\mathrm{BN})$, a widely applied system to conduct uncertain knowledge representation and reasoning. A comparison has been made between the modeling and analysis of fault-trees[23,4], reliability block diagrams[29] and BNs, which has established that they possess a significant advantage over the traditional frameworks. Bayesian network models designed for reliability evaluation can be obtained through the conversion of the traditional ones [6]. Bobbio et al. [4] presented an algorithm of mapping a fault tree with general gates model into an equivalent Bayesian network representationvand Kim [21] presented a general method to convert a reliability block diagram to a Bayesian network. Based on the theory of BN, reference [35] makes the reliability assessment for high-speed train bearing under the extreme sample size which solves the reliability life of the bearing; Reference [34] assesses the reliability of key structure of $\mathrm{C} 70$ gondola car which follows Gaussian distributions for extreme sample size. Dorociak, R.[9] presented a method to analyze in a probabilistic manner the reliability regarding an innovative autonomous railway vehicle. It renders a support to the modeling of the failure propagation within the specification of complex systems. When the failure propagation is translated into a Bayesian network, a sophisticated probability analysis is made possible. Guo J, Wilson A G. [12] proposed a Bayesian approach to make an assessment of the reliability of multi-component systems, which facilitates us, with the use of the multilevel information available, to evaluate the system, the subsystem, and the component reliability. We can safely confirm that the research into railway vehicle reliability is still in BN stage.

However, in conventional BN-based analysis, it is a static model which stands for a joint probability distribution at a time interval or a fixed point. Meanwhile, the dependency among variables is not submitted[20,21] in the construction of a BN model. [32, 33]. Yet Dynamic Bayesian Networks (DBNs) are enduring extension of BNs, which make it convenient for us to acquire explicit modeling of temporal dependencies. DBNs render us an unique technique to model time-dependent changes in an intuitive way by means of a robust probabilistic framework [16]. And, the learning and reasoning engine of DBN makes it a possibility for complex interactions among the components of EMUs to be taken into consideration with regard to reliability assessment. Many studies, with the use of DBN to estimate system reliability, have been put forward, while Boudali $\mathrm{H}$. et al. [5] presented that, through the transformation of Dynamic Fault Trees (DFT) into DBN, the integration of the dynamic aspect shall be acquired. As for Portinale et al. [24], a software called Reliability Analysis with Dynamic Bayesian Networks (RADYBAN) has been employed, it supports an automatic translation from DFT into a DBN and presents a method of reliability modeling. Weber and Jouffe [31] had a methodology employed to facilitate a developing dynamic object oriented Bayesian networks to formalize complex and dynamic models, with the model structure deduced from the malfunctioning (knowledge represented through FMECA method) and functional analysis (knowledge formalized by SADT method).

One of the major limitations of the DBN framework, however, is the complexity of the system that can be tractably modeled as a DBN [22]. Current tools, which are based on the assumption of a pre-built DBN, have some disadvantages, including a lack of effective modeling power in depicting both functional and temporal dependencies between components. In this paper, a new modeling approach to DBN generation is submitted, which can be applied to the system made up of certain components and different types of flows propagating through them, with each component possessing Conditional Probability Table (CPT) for a description of the relations between input-output flows. The Component-based CPT (Conditional Probability Table) and Time-dependent CPT are used to describe functional dependencies and temporal dependencies respectively. As the complexity and size of the system cannot be modeled in a tractable way as a DBN, a Breadth-First-Search (BFS) algorithm is introduced for the construction of the DBN model in an automated manner.

The paper has the structure of organization as follows. Section 2 offers a general overview of DBN and its inference scheme. In Section 3, Basic concepts of a dynamic system model and the componentbased CPTs(Conditional Probability Tables) are introduced. Based on these concepts and a trace- back algorithm, an automated DBN generation procedure is proposed in Section 4. In Section 5, an application of the proposed approach to reliability analysis is conducted in a traction drive system of the case study of EMUs, with the conclusions reached in Section 6.

\section{An overview of DBN}

Bayesian Networks (BNs) are in the form of directed acyclic graphs for uncertainty reasoning, with the nodes representing variables and links defining probabilistic dependences between variables. The CPTs connected to the nodes determine the extent to which the linked nodes depend on each other. On the basis of the conditional independency theorem, BN carries out a factorization of the joint probability distribution of a set of random variables $\left\{X_{1}, X_{2}, \cdots X_{n}\right\}$ with local dependencies in mind. In this aspect, the distribution mentioned above can be allowed to be decomposed as what is derived from the probabilities of the nodes given their immediate parents:

$$
P\left[X_{1}, X_{2}, \cdots X_{n}\right]=\prod_{i=1}^{n} P\left[X_{i} \mid P a\left(X_{i}\right)\right]
$$

Where $\mathrm{Pa}\left(X_{i}\right)$ is the parent node of variable $X_{i}$. The computation is based on the probabilities of the parent's states and the CPT. For instance, let us consider two nodes $X_{1}$ and $X_{2}$ with two states ( $S_{1}$ and $S_{2}$ ) each structuring the $\mathrm{BN}$. This CPT is defined as a matrix:

$$
P\left[X_{2} \mid P a\left(X_{2}\right)\right]=\left[\begin{array}{ll}
p\left(X_{2}=S_{1} \mid X_{1}=S_{1}\right) & p\left(X_{2}=S_{1} \mid X_{1}=S_{2}\right) \\
p\left(X_{2}=S_{2} \mid X_{1}=S_{1}\right) & p\left(X_{2}=S_{2} \mid X_{1}=S_{2}\right)
\end{array}\right]
$$

By means of relevant temporal dependencies that capture the dynamic behavior of the domain variables between representations of the static network at different times, the static BN can be extended to get a DBN model. Early work in regard to the application of BNs to dynamic domains $[1,2,10,14]$ has rendered us formalisms of DBN, with two types of approaches distinguished in the representations of a 
dynamic Bayesian network, i.e., instant-based (time-sliced) type and interval-based (event-based) type [5]. The former involves discretizing the time line and associating a node to every time instant. Basically, the models have been acquired with the generation of a BN for a specific time instant, with the same structure repeated for every time instant over the time range of interest. Example includes Temporal Bayesian Networks (TBN) [15], Modifiable Temporal Belief Networks (MTBN) [1] and Dynamic Object Oriented BN (DOOBN)[31]. In Ref. [31], P. Webber et al. applied a 2-time-slice DBN to model temporal dependencies, with the model structure deduced from the functional analysis. Another representation of DBN is event-based approach. As for the latter, the time line is sliced into a finite number of time intervals, with just one BN generated, and each node possessing a finite number of states equalizing to that of time intervals. The involved examples are Temporal Nodes Bayesian Networks (TNBN) [2], Net of Irreversible Events in Discrete Time (NIEDT)[10] and Discrete-Time Bayesian network (DTBN)[23], where a node stands for an event, with a certain outcome to take place at a certain time interval. According to the fact that our DBN model features the fixed structure that can be repeated for every time instant, this paper adopts the time-sliced type.

The DBNs allow us to taking time into consideration, with the definition of different nodes to stand for the variables at different time slices. The joint distribution of probability regarding a set of randomly variables at time $t+\Delta t$ can be decomposed as what is derived from the probabilities of the nodes given their immediate parents:

$P\left[X_{1}^{t+\Delta t}, X_{2}^{t+\Delta t}, \cdots X_{n}^{t+\Delta t}\right]=\prod_{i=1}^{n} P\left[X_{i}^{t+\Delta t} \mid X_{i}^{t}, P a\left(X_{i}^{t}\right), P a\left(X_{i}^{t+\Delta t}\right)\right](3)$

where $X_{i}^{t+\Delta t}$ and $X_{i}^{t}$ are the copies of $X_{i}$ in two consecutive time slices with a time interval of $\Delta t, P a\left(X_{i}^{t}\right)$ and $P a\left(X_{i}^{t+\Delta t}\right)$ are the parent sets of at the time slices $t$ and $t+\Delta t$ respectively. Depending on the dynamic transition and physical features of the stochastic process of interest and thus the conditional inter- dependencies that need to be modeled, either aforementioned parent set could be empty.

Defining these impacts as transition probabilities between the states of the variable at time step $t+\Delta t$ and those at time slice $t$ leads to the definition of CPTs that are relative to inter-time slices. With this model, the future slice $t+\Delta t$ is conditionally independent of the past given the present $t$, which means that the CPT respects the Markov properties. This CPT is defined as:

$$
P\left(X^{t+\Delta t} \mid X^{t}\right)=\prod_{i=1}^{N} P\left(X_{i}^{t} \mid \operatorname{Pa}\left(X_{i}^{t}\right)\right)
$$

where $X_{i}^{t}$ is the $i$ th node at time $t$ and $P a\left(X_{i}^{t}\right)$ are the parents of $X_{i}^{t}$ in the graph. The nodes in the first slice of a DBN do not have any parameters associated with them, but each node in the second slice of the DBN has a conditional probability table (CPT) for discrete variables, which defines $P\left(X_{i}^{t} \mid P a\left(X_{i}^{t}\right)\right)$ for all $t \geq 1$. Several inference methods for a DBN can be used, i.e., forwards-backwards algorithm, unrolled junction tree, and the frontier algorithm. For the evaluation of the DBN presented in this article, a Netica procedure[7] based on the junction tree is used.

\section{Component-based CPT}

This modeling method involves a component-based approach, i.e., any system is modeled as a group of interconnected components. Different classifications of energy, information or materials are transferred in the form of flows by means of the connections between the components, with each one possessing some input or output relationships that quantified through the association of a conditional probability table. Generally speaking, components in the system serve as the building blocks and flows make their movements among the components.

\subsection{Basic concepts}

In order to define Component-based CPT for DBN formally, we, first, capture the breakdown structure of the system into physical or functional components; second, identify the input and output flows including types and finally model the system as networked components with input and output flows.

\subsubsection{Components}

A component is defined as any of the elementary unit of a system, including all the electrical and mechanical devices. They are in the form of either active components such as coolers and pumps, or passive components such as wires and pipes. Symbolized as a simple circle, each component has a label, with some arrows pointing outward or inward, acting as its output or input paths in a respective manner. CPT, the vital part of component models, defines how output values are formed on the basis of input values. Here three kinds of components are defined: flow-intervened components, flow-collaborated components and flow-dependent components. Each one can take on several states or failed modes, and as far as each state, there is a definition of time-dependent CPT. Take the pressure control as an example. It involves several failed modes identified from previous experience and expert judgment. An expert can predict at least the following software malfunctions, i.e., the low-stuck, high-stuck or oscillating control signal.

\subsubsection{Flows}

A system can be considered as a networked topology structure of components along flow paths. A flow is generally defined as any energy, information or materials propagating from one component to another. Various discrete scales have been put in place in the previous work in engineering design to identify design dependencies between components in respect to the flows of material, energy or information among functional components of systems during their concept development[28]. Energy, matter and information are considered basic concepts in any design problem. It is the flow of these three concepts that concerns designers. Flows are equipped with some physical properties vital to system analysis. As regards components, they can have an effect on these properties with flows passing through them. For example, an oil flow has a possession of physical properties like pressure, temperature, concentration and the flow rate. Likewise, their range of variation is expected to get specified.

\subsection{Component-based CPT}

Component-based CPTs are defined in accordance with the types of basic components tying together the input and output flows. The use of a component-based CPT allows us to obtain the output values for combination of varying input. And thanks to the component-based CPTs, we can acquire a model of the propagation involving several failure modes in the system through the input-output flows. Then, the hypothesis of independence between components made for traditional reliability assessment is not necessary. As a matter of fact, component-based CPTs make it possible for us to compute repercussions of 
interdependence components to the system reliability and introduce uncertainty by putting probabilities in place at the interval of value $[0,1]$.

\subsubsection{Flow-collaborated components and its BN formalization}

A sample Component-based CPT for a flow-collaborated component is shown in Fig.1(a) The flow-intervened component has the same type of flow input and output. The output serves as a function or functionality condition in respect to the inputs. With the input from another component of the system, the CPT is an internal parameter embedded in the component. For the purpose of reaching the conversion algorithm from flow-intervened component to $\mathrm{BN}$, we have adopted the following convention: Given a generic binary input flow or component $\mathrm{CMP}$, we denote with $\mathrm{CMP}=1$ the component failure and with $\mathrm{CMP}=0$ the component normal. With the usual hypothesis that input flow or component failures are distributed in an exponential way, the probability of the occurrence of the primary event $\mathrm{CMP}=1$ at time $t$ is $\exp (-\lambda \times t)$, where $\lambda$ acts as the failure rate of input flow or component.

(a)

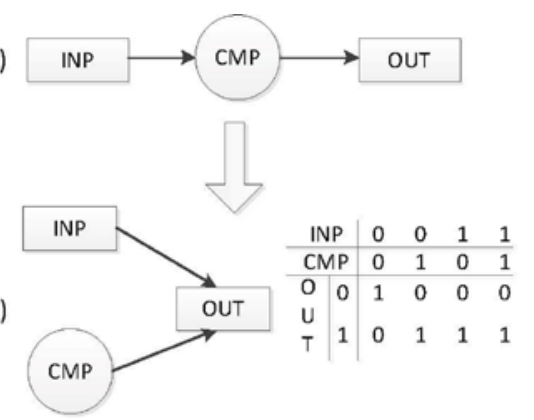

Fig. 1. Component-based CPT for a Flow-collaborated Component

Fig.1(b) demonstrated the conversion of a flow-collaborated component. Input flow(INP)and flow-collaborated component (CMP) are assigned to probabilities in advance(in agreement with the probability of the occurrence of the primary event INP $=1$ or $\mathrm{CMP}=1$ ), and output flow is assigned to its CPT. The output fails when flow-collaborated component or input flow falls into a failed state.

\subsubsection{Flow-intervened components and its $B N$ formalization}

A sample Component-based CPT for a flow-intervened component is shown in Fig.2(a). The flow-intervened component has one type of flow input and another type of flow output. The output is a function or functionality condition of the inputs. With the input coming from another component of the system, the CPT acts as an internal parameter of the component. In order to reach the conversion algorithm from flow-intervened component to BN, we adopt the same convention mentioned above.

Fig.2(b) shows the conversion of a flow-intervened component. Input flow(INP) is assigned prior probabilities (coincident with the probability of occurrence of the primary event $I N P=1$ ), and flow-intervened component are output flow are assigned CPT. CSCSIT[13] is potentially to help improve the Flow-intervened components' CPT modeling for that it can provide a reliability parametrized componentbased modeling structure. In CSCSIT, a component failure occurs when the conceptual stress of the input flow exceeds its conceptual strength. Therefore, the conditional probability $P_{i n t}$ for the component CMP failure is given by:

$$
P_{\text {int }}=\operatorname{Pr}\left(C S t e_{I N P} \geq C S t n_{C M P}\right)
$$

Here $C S t e_{I N P}$ is the conceptual stress of the input flow and $\operatorname{CStn}_{C M P}$ (a)

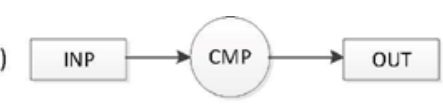

(b)

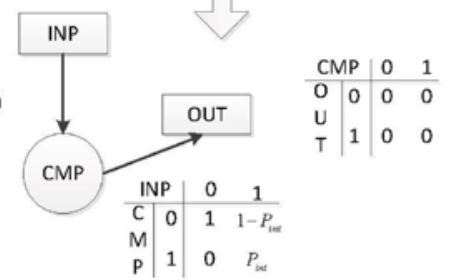

Fig. 2. Component-based CPT for a flow-intervened component

is the conceptual strength for the component CMP. One nice feature of the CSCSIT is that it can represent the uncertainty by conditional probability $P_{\text {int }}$.

\subsection{Time-dependent CPT}

In the simplest form, as for the component in Section3.2, the component is either in failed or work state. However, there is over one failure mode for a component in the general case. For example, a traction motor may be either overheating $(\mathrm{O})$ or in operation (I). In our work, the failure modes of a component are defined by states, with a description of its ability or inability to output the desired flows. The multi-state of components can be modeled as a DBN formalization.

(a)

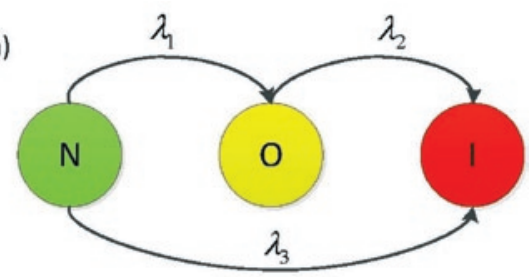

(b)

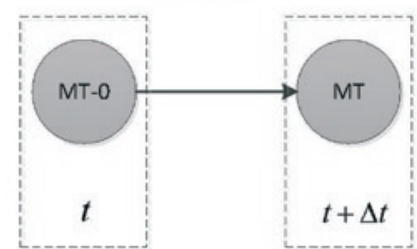

Fig.3 Markov model for state transition modeling of traction motor

Consider a traction motor with three states, which can be envisaged as: normal $(\mathrm{N})$, overheating $(\mathrm{O})$, and in operation (I). An Markov model of traction motor reliability is easy to build, which is shown in Fig.3(a). Then, independent components of the process are modeled by using DBN that is equivalent to an independent MC: Firstly, the traction motor is modeled by a discrete random variable $\mathrm{X}$ with states $\{\mathrm{N}, \mathrm{O}, \mathrm{I}\}$. Next two nodes are defined to model the random variable at time slices $t$ and $t+\Delta t: C M P(t)$ and $C M P(t+\Delta t)$. Kinked by an arc representing the dependency between the component states at time slice $t$ and its states at time slice $t+\Delta t$, these nodes are both rendered a description by the states $\{\mathrm{N}, \mathrm{O}, \mathrm{I}\}$. With the assumption of the constant failure rates of normal $(\mathrm{N})$, overheating $(\mathrm{O})$ and in operation (I) denoted as $\lambda_{1}, \lambda_{2}$ and $\lambda_{3}$, usually estimated by using historical data, the aforementioned transition gets modeled in the corresponding DBN through the conditional probability. In order to get clarified, the Markov model and the equivalent DBN in regard to state transition modeling of the traction motor are demonstrated in Fig.3(b), with T1 at $t+\Delta t$, the time-dependent conditional probabilities, presented in Table1. 
Table 1. Time-dependent CPT of the Traction Motor at $t+\Delta t$

\begin{tabular}{c|cccc}
\hline \hline \multicolumn{2}{c}{$C M P(t)$} & $\mathbf{N}$ & $\mathbf{0}$ & I \\
\hline & $\mathrm{N}$ & $\exp \left(-\lambda_{1} \times \Delta t\right)+\exp \left(-\lambda_{3} \times \Delta t\right)-1$ & $1-\exp \left(-\lambda_{1} \times \Delta t\right)$ & $1-\exp \left(-\lambda_{3} \times \Delta t\right)$ \\
$C M P(t+\Delta t)$ & 0 & 0 & $\exp \left(-\lambda_{2} \times \Delta t\right)$ & $1-\exp \left(-\lambda_{2} \times \Delta t\right)$ \\
& & 0 & 0 & 1 \\
\hline \hline
\end{tabular}

\section{Modeling approach}

Previous sections described the necessary details and settings of modeling a system. Her we move on to the second phase involving the procedure of the automated DBN construction, where a BreadthFirst-Search (BFS) algorithm works on the provided model to generate the Structure of DBN in the system. The depth-first search is used to identify reencountered events, and practise some simplification in the end. The main interest in such an approach to render a reliability modeling from DBN consists in the propagation of the components' failure through the input/output flow of the system. However, the operation to model complex systems makes a methodology a necessity in an effort to get the DBN's structure specified, with four main steps involved in the proposed modeling approach as follows:

1. Create the model of component and input/output flows for the analysis of system.

2. Identify the target event and system boundaries that have an active influence on the propagation of components' failures.

3. Structure a learning of DBN based on BFS.

4. We will endeavor to formalize the DBN from this System representation.

\subsection{Step 1: System modeling}

With the previous concepts introduced, we are allowed to model a variety of complex technical systems, including both configuration network and CPT description. The former's configuration is simply modeled with appropriate components to get connected to each other in a desired manner. The components regarding CPT will simulate how the system operates in a comprehensive way. As far as the system modeling in DBN construction is concerned, we will have two procedures illustrated in an explicit way in this step.
1) Malfunction knowledge acquisition: Previous resources in regard to malfunctioning knowledge are supposed to be acquired in the first place in an effort to offer a basis for System modeling. The resources can be obtained in two aspects: empirical knowledge from domain experts and the accepted knowledge from existing design and construction standards. The collected knowledge can be expressed in table. 2

The components of EMU traction system are listed in the first row and the column in table.2, with their meanings queried to what is listed in Section 5.1 and the connection between components is represented by the flow of energy, matter and information.

2) Configuration model creation: Developed from a direct mapping of the functional model to generic components by using the input and output flows, the configuration model represents the actual design under consideration. Called the component basis and the flow taxonomy, a dictionary of flows and components as introduced in [27,17], is presented in the methodology involved in this paper, where the configuration layout of the system is captured by means of configuration flow graphs (CFGs), with blocks representing system components and lines connecting the blocks the material, energy, or information among the components( to be clarified, with solid lines representing material, dashed lines energy and dash dotted lines signals). An example of CFG is shown in Fig.4.

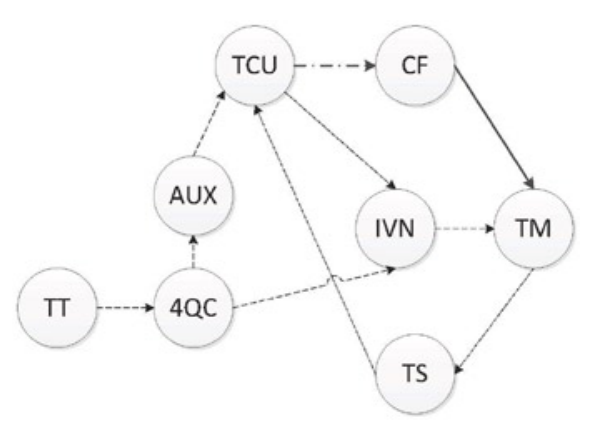

Fig. 4. Configuration flow graphs of EMU traction system
Table 2. Component connection table of EMU traction system

\begin{tabular}{|c|c|c|c|c|c|c|c|c|}
\hline $\begin{array}{c}\text { Compo- } \\
\text { nents }\end{array}$ & TT & $4 Q C$ & AUX & TCU & INV & $\mathrm{CF}$ & $\mathrm{TS}$ & $\mathrm{TM}$ \\
\hline TT & & Energy & & & & & & \\
\hline $4 Q C$ & & & Energy & & Energy & & & \\
\hline AUX & & & & Energy & & & & \\
\hline TCU & & & & & $\begin{array}{l}\text { Informa- } \\
\text { tion }\end{array}$ & $\begin{array}{l}\text { Informa- } \\
\text { tion }\end{array}$ & & \\
\hline INV & & & & & & & & Energy \\
\hline $\mathrm{CF}$ & & & & & & & & Matter \\
\hline TS & & & & $\begin{array}{l}\text { Informa- } \\
\text { tion }\end{array}$ & & & & \\
\hline $\mathrm{TM}$ & & & & & & & $\begin{array}{l}\text { Informa- } \\
\text { tion }\end{array}$ & \\
\hline
\end{tabular}

\subsection{Step 2: Target event identification}

A target event is defined by assigning specific values to some of the system parameters. The target identification process involves two steps:

1) System boundaries identification: we firstly determine the border of configuration model. The hypothetical lines, which are covered by BFS algorithm to determine the lines, are called system boundaries. A component located at system boundary is a starting point for the BFS algorithm.

2) Target event: We can specify any state of the starting point as a target event, including some parameters of a flow, like temperature pressure, flow rate, or pressure. The values can be selected within the range of these parameters. Under the definition of a sample target event, the output of pump p2 is zero or the temperature of flow $\mathrm{fl}$ is high. Then, a DBN synthesis algorithm starts from the point of occurrence of the target event, and relevant components, after which 
the system reliability condition can be determined by tracing back all possible paths ending into the target event.

\subsection{Step 3: DBN synthesis}

A DBN construction is developed in this stage to integrate the configuration of the system in a simultaneous way, with the target event defined by what is completed in the previous step. What is mainly involved in procedure of the DBN construction is a BFS algorithm to acquire all the paths leading into the target event. Depth-first search is one of the basic algorithms regarding graph theory, which is commonly employed to a test in connectivity or compute the shortest paths of underweighted graphs of single source [3]. With the target event is defined and all of the required CPT settings completed, the BFS algorithm is supposed to start from the point of occurrence of the target event, and examine the CPT of the components to acquire all of their potential causes. The algorithm switches from one component to another in a reve rse direction of the flows. The synthesis of a DBN construction involves a determination of the system boundaries, network structure, as well as the Markov chain process, during which process three procedures are illustrated explicitly as follows:

1) Component added (BFS tree): Starting from the target event, the frontier of BFS makes an outward expansion with each step, visiting all of the same-depth components before visiting another at the next depth. Within a step of such top-down approach, each component checks all of its neighbors to see if there are overlooked ones, with its CPT searching to locate the rows with the output value of interest. In case of a CPT with one component leading to that output value, the previously unvisited component will be added to the frontier and marked as visited by setting its parent variable. The procedure is continued until each component at the system boundary is touched. This algorithm yields a BFS tree and The pseudo code is detailed as Table.3.

Table 3. Pseudo code of BFS

\begin{tabular}{|l|}
\hline breadth-first-search (components, target event) \\
\hline frontier $\leftarrow\{$ target event $\}$ \\
next $\leftarrow\{\}$ \\
parents $\leftarrow[-1,-1, \ldots,-1]$ \\
while frontier $=\{\}$ do \\
for $\mathbf{c} \in$ frontier do \\
for $\mathbf{n} \in$ neighbors $[\mathbf{c}]$ do \\
if parents[n] $]=-1$ then \\
parents $[\mathbf{n}] \leftarrow \mathbf{c}$ \\
next $\leftarrow$ next $\cup\{\mathbf{n}\}$ \\
end if \\
end for \\
end for \\
frontier $\leftarrow$ next \\
next $\leftarrow\{\}$ \\
end while \\
return tree \\
\hline \hline
\end{tabular}

the real-world situation represented by a Bayesian node. When a component is considered in the BFS algorithm, the BN formalization of its $\mathrm{CPT}$ is created, with the rows involving the output value of interest set as its inputs. Each of these inputs will be checked for need to further expand. However, with this multi-state components considered, the DBN formalization of its CPT is created and two nodes are defined to model the variable in a random way at time slices $t$ and $t+\Delta t$. An example of traction motor(TM) is shown in Fig. 5.

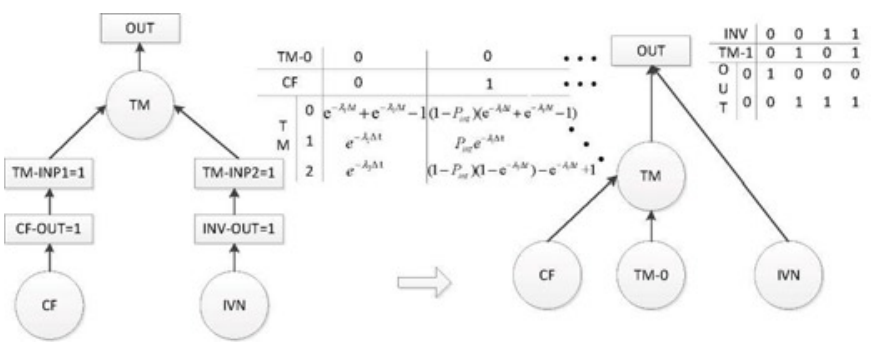

Fig. 5. Structure Learning of Traction Motor(TM)

In Fig. 5, there are CF (cooling fan), TM Flow-collaborated, INV (traction inverter) and TMF low-intervened components. TM itself is a Time-dependent component. Based on the generation principle of CPT, Fig. 5(a) can be transformed into Fig. 5(b) by structure learning.

\section{Example}

\subsection{DBN model of EMU traction system}

The CRH5 high-speed EMU is designed for a speed of $250 \mathrm{~km} / \mathrm{h}$, which consists of two symmetrical traction units $(\mathrm{Mc}(1), \mathrm{M} 2(2)$, $\mathrm{TP}(3)$ and M2(4) comprise tractions of unit 1; T2(5), TPB(6), MH(7) and $\mathrm{Mc}(8)$ comprise traction unit 2).Modern mechatronics technology and its new features have led to a continuously improvement of the construction of the traction unit structures. A traction unit mainly includes traction transformer(TT), auxiliary inverter(AUX), traction inverter(INV), traction control unit(TCU), four-quardant rectifier(4QC), cooling fan (CF), traction motor(TM) and its temperature sensor(TS). The traction unit can be highly complex due to the systematic use of new technologies and be functional dependency due to the interactions between system functions with the characteristics of a variety of structures.

In traction unit 1 , four-quardant rectifier obtains power through the traction transformer at the bottom of the vehicle, with the power transferred to the traction inverter and the auxiliary inverter. Traction control unit gets power through the auxiliary inverter and control the air volume of fan following the signals collected by temperature sensor, Traction inverter is connected to the traction motors through the terminal blocks of traction inverter. The traction motors have a cooling fan and a temperature sensor in order to monitor and reduce the motor temperature. Mechanical energy from the output of the traction motor is delivered to the wheels through the OUT1. Fig. 6(a) shows the configuration model of the traction system of CRH5. According to the DBN modeling approach proposed in Section 4, we have chosen

\section{2) DBN Structure learning:}

Structure learning aims at figuring out a proper directed acyclic graph (DAG), and confirming the failure mechanism among nodes. In accordance with the establishment of BFS tree, explicit DAG and failure mechanism among the components can then be revealed by the input and output flows. The definition of the failure mechanism is formalized at the level of the system, while the description of the failure mode is made at the level of component. In line with this functioning, the malfunctioning of the system is induced with a consideration of the normal and abnormal states of the components, with every component in

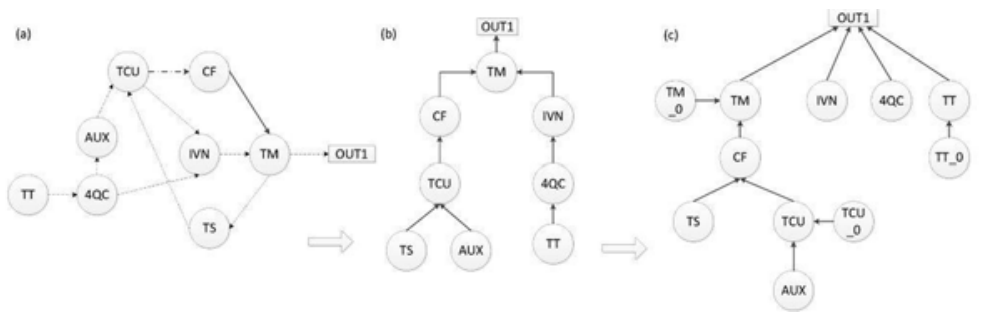

Fig. 6. DBN Model of EMU Traction System 
energy output of traction motors OUT1 as a target event and a certain BFS tree is shown in Fig. 6(b). Then, the structure learning of DBN is based on the DBN formalization of components' CPTs, and finally, we obtained the DBN shown as Fig. 6(c).

\subsection{Reliability evaluation}

Within the failure statistic data of the traction system of CRH5 which is running in Beijing- Harbin high-speed railway, we have conducted a calculation of the reliability indexes of the CRH5 [4,6,21], with the time range set from September 15, 2011 to June 20, 2015 respectively. With such an immense amount of data, we have just presented the results with respect to the reliability indexes of the components mounted on the traction of unit 1 which is running in BeijingHarbin railway. The results are presented in Table.4. In Table.4, where MDBF is the abbreviation of Mean Distance Between Failures.

Table.4 Reliability Indexes of the Components

\begin{tabular}{cccc}
\hline \hline Component & $\begin{array}{c}\text { Number of } \\
\text { failure }\end{array}$ & $\begin{array}{c}\text { Average failure } \\
\text { Rate(Time/1E5km) }\end{array}$ & MDBF(1E5km) \\
\hline TM & 89 & 0.003415 & 292.8258 \\
TCU & 113 & 0.005621 & 177.9043 \\
TT & 77 & 0.002906 & 344.1156 \\
INV & 85 & 0.003205 & 312.0125 \\
4QC & 75 & 0.002655 & 376.6478 \\
TS & 121 & 0.006528 & 153.1863 \\
AUX & 80 & 0.003137 & 318.7759 \\
CF & 31 & 0.001312 & 762.1951 \\
\hline \hline
\end{tabular}

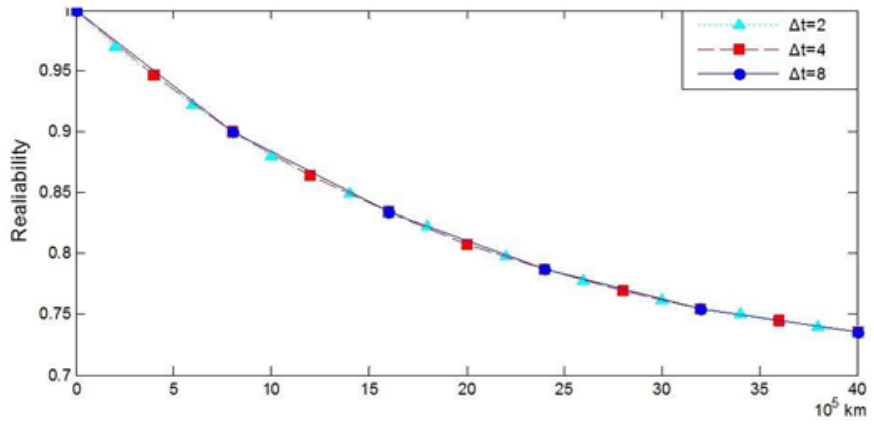

Fig. 8. Reliability of the Traction System without Components' Failure

a longer running time. Here the DBNs are extended $1 \mathrm{E} 5 \mathrm{~km}$, and the DBNs structure of what is extended within the $40 \mathrm{E} 5 \mathrm{~km}$ is presented in Fig.8.

When no component failure occurs, time interval, $\Delta \mathrm{t}$, the system reliability is rarely affected for the reason that the extension of DBNs and the conditional probability of time slices involving each component are rooted on the exponential distribution of components. As we have expected, with the increase in time, the reliability of the traction system decreases in a corresponding way. According to the DBN model of the traction system and what is obtained from the reliability indexes of the components of traction system, we can calculate that: In the $40 \mathrm{E} 5 \mathrm{~km}$, the system still possess a reliability of $73.326 \%$, with an indication of $t$ sufficient secure on the part of the traction system.

When a certain component is abnormal, a calculation and plot of the reliability values shall be carried out. As is shown in Fig.8 (a), there comes a rapid decrease of reliability before the overheating of

The reliability evaluation phase of the traction system is established with the application of Netica software shown in Fig.7. Take the traction system as an example, parent nodes TM_0, TS, Table. 5 Two Case of Reliability Evaluation

\begin{tabular}{ccccccccc}
\hline \hline Component & TM & TCU & TT & INV & 4QC & TS & AUX & CF \\
\hline Case1 & Overheating & Normal & Normal & Normal & Normal & Normal & Normal & Normal \\
Case2 & Normal & Normal & Normal & Normal & Normal & Normal & Fail & Normal \\
\hline \hline
\end{tabular}
AUX,TCU_0, TT_0, INV and 4QC at the component state layer stand for the states of components, excluding the faults of components. OUT, the unique child node represents the state of the traction system. Child node OUT has two states, i.e., normal one and failed one, and the probability that the normal one of OUT represents the value of the system reliability. For the purpose of modeling the temporal evolution of a system, we have selected two time slices for multi-states components, e.g., TM represents the current time step of traction motor, and TM_ 0 the previous time step. The time interval $\Delta \mathrm{t}$ could be $1 \mathrm{E} 5 \mathrm{~km}$ or $1 \mathrm{E} \overline{5} \mathrm{~h}$. A wealth of time slices is in agreement with a smaller the value of $\Delta \mathrm{t}$, hence rendering Netica
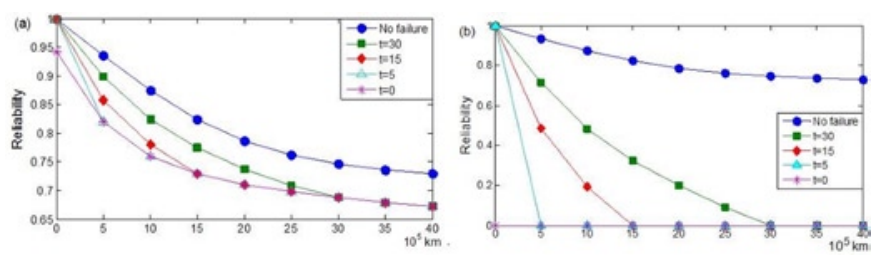

Fig. 9. Reliability of the traction system when a certain component is abnormal

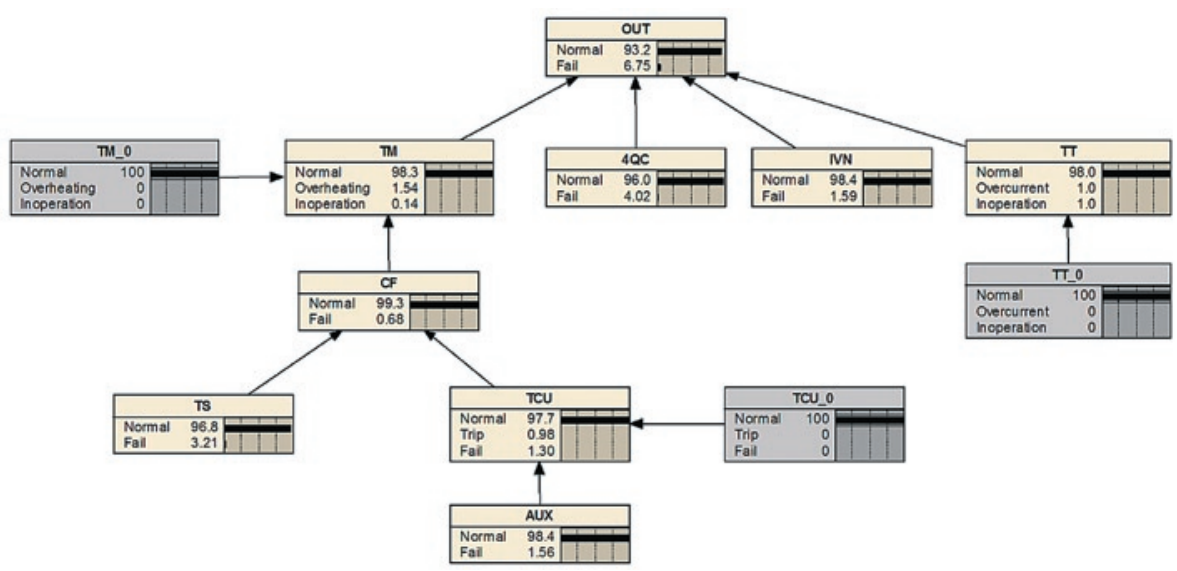

traction motor is detected, and once the traction motor goes in operation, the reliability of traction system decreases to 0 with the immediate overheating of traction motor after the system is started, rendering the motor a fatal weakness of the traction system and making it a necessity the improvement of the reliability of the traction motor value to the fullest degree.

As is illustrated in Fig.8 (b), there comes the fault of auxiliary inverter immediately after the system is started, with the reliability decreasing to a lower level lower when the no fault occurs. In the $40 \mathrm{E} 5 \mathrm{~km}$, the system still possesses a reliability of $68.28 \%$. With the occurrence of the fault at a certain intermediate time, the reliability decreases to the value when the fault occurs at $t=0$. This arises from the fact that the auxiliary inverter is a flow-intervened component, 
and its failure has little effect on the normal operation of the traction system, but with a decrease of the reliability regarding the entire system.

\section{Conclusion}

DBN serves as a powerful tool for knowledge representation and reasoning in a complex mechatronic system. A new system of modeling approach for DBN generation is presented in this paper, with the introduction of a component-based configuration model made up of some components and different types of flows propagating through them and a Breadth-First-Search (BFS) algorithm for the automated construction of the DBN model. The Configuration model comprises some components and different types of flows propagating through them, with each component possessing a CPT description of its inputoutput flows relations. As the size and complexity of the system cannot be tractably modeled as a BN, a Breadth-First-Search (BFS) algorithm is introduced for automated construction of the DBN model. Given that traditional DBN framework can not be tractably modeled, our method offers a good description of functional and temporal dependencies between components, which turns out to be a satisfying solution with regard to the modeling of complex systems.

We have demonstrated in this paper the application of the proposed approach to reliability assessment of traction drive system regarding high-speed EMUs, with the reliabilities evaluated by means of netica, taking into account two important features of dependency between components and multi-state components. An application of the proposed Bayesian network models facilitates the evaluation of the reliability of traction drive system at any given time. Results have established that the DBN-based approach can perform in a more accurate way than the traditional static one in regard to modeling the evolution of the probabilistic dependencies within a complex system over time.

It may be concluded that, with the use of DBN in the reliability assessment of complex mechatronic systems, we can not only avoid problems such as the failures' dependencies and the multi-state elements, a common thing in traditional static approach, but also help analysts to conduct probability updating, which is of great significance in the real-time monitoring, and evaluation of mechatronic systems. Future work will place an emphasis on the investigation of a real-time intelligent reliability evaluation software with the application of automatic data acquisition and the proposed DBN modeling approach for an entire system, such as a EMU system equipped with thousands of flow-intervened or flow-collaborated components.

\section{Acknowledgment}

The authors gratefully acknowledge the support provided by the research project (Grant No. RCS 2016ZZ002) of State Key Laboratory of Rail Traffic Control and Safety (RCS) in China.

\section{References}

1. Aliferis C F, Cooper G F. A Structurally and Temporally Extended Bayesian Belief Network Model: Definitions, Properties, and Modeling Techniques. Eprint Arxiv, 2013.

2. Arroyo-Figueroa G, Sucar L E. A temporal Bayesian network for diagnosis and prediction. Fifteenth Conference on Uncertainty in Artificial Intelligence. Morgan Kaufmann Publishers Inc. 1999:13-20.

3. Beamer S, Asanović K, Patterson D. Direction-optimizing breadth-first search. Scientific Programming 2013; 21(3-4): 137-148, https://doi. org $/ 10.1155 / 2013 / 702694$.

4. Bobbio A, Portinale L, Minichino M, et al. Improving the analysis of dependable systems by mapping fault trees into Bayesian networks. Reliability Engineering \& System Safety 2001; 71(3): 249-260, https://doi.org/10.1016/S0951-8320(00)00077-6.

5. Boudali H, Dugan J B. A discrete-time Bayesian network reliability modeling and analysis framework. Reliability Engineering \& System Safety 2005; 87(3): 337-349, https://doi.org/10.1016/j.ress.2004.06.004.

6. Cai B, Liu Y, Liu Z, et al. Using Bayesian networks in reliability evaluation for subsea blowout preventer control system. Reliability Engineering \& System Safety 2012; 108: 32-41, https://doi.org/10.1016/j.ress.2012.07.006.

7. Cai B, Liu Y, Ma Y, et al. Real-time reliability evaluation methodology based on dynamic Bayesian networks: A case study of a subsea pipe ram BOP system. Isa Transactions 2015; 58: 595-604, https://doi.org/10.1016/j.isatra.2015.06.011.

8. Chateauneuf A, Cocheteux F, Deffarges F, et al. Reliability analysis of screwed connections in high-speed trains, considering fatigue, corrosion, and imperfect maintenance operations. Proceedings of the Institution of Mechanical Engineers Part O Journal of Risk \& Reliability 2011; 225(3): 293-306, https://doi.org/10.1177/1748006X11402738.

9. Dorociak R. Early probabilistic reliability analysis of mechatronic systems. Reliability \& Maintainability Symposium. IEEE, 2012:1-6.

10. Gala'n SF, Di'ez FJ. Modeling dynamic causal interactions with Bayesian networks: temporal noisy gates. CaNew', the 2nd International Workshop on Causal Networks held in conjunction with ECAI 2000, Berlin, Germany, August 2000; 1-5.

11. Guangzu S. Efforts to create a new situation of scientific development of railway, better services for economic and social development and the people. Railway Economics Research 2012; 1: 1-26.

12. Guo J, Wilson A G. Bayesian methods for estimating system reliability using heterogeneous multilevel information. Technometrics 2013 , 55(4): 461-472, https://doi.org/10.1080/00401706.2013.804441.

13. Huang Z, Jin Y. Extension of stress and strength interference theory for conceptual design-for-reliability. Journal of Mechanical Design 2009; 131(7): 1-11.

14. Joung E, Kim G, Lee J, et al. Reliability Analysis of New Type Electric Multiple Unit. Computer Applications for Modeling, Simulation, and Automobile 2012: 213-220,https://doi.org/10.1007/978-3-642-35248-5_30.

15. Kanazawa K. Reasoning about time and probability. Brown University, 1994.

16. Khakzad N. Application of dynamic Bayesian network to risk analysis of domino effects in chemical infrastructures. Reliability Engineering \& System Safety 2015; 138: 263-272, https://doi.org/10.1016/j.ress.2015.02.007.

17. Kurtoglu T, Tumer I Y. A Graph-Based Fault Identification and Propagation Framework for Functional Design of Complex Systems. Journal of Mechanical Design 2008; 130(5): 680-682, https://doi.org/10.1115/1.2885181.

18. Lee H, Joung E, Kim G, et al. A study on management system for reliability analysis in advanced EMU. Vehicle Power and Propulsion Conference (VPPC) 2012 IEEE. IEEE, 2012: 1266-1269.

19. Li C, Qiao C, Zhang Y, et al. Reliability optimization design of connecting rod of locomotive traction equipment. Archive Proceedings of the Institution of Mechanical Engineers Part C Journal of Mechanical Engineering Science 1989-1996; 203-210. 
20. Liu J, Li S, Jiang Y, et al. Reliability evaluating for traction drive system of high-speed electrical multiple units. Transportation Electrification Conference and Expo (ITEC), 2013 IEEE. IEEE, 2013: 1-6.

21. Man C K. Reliability block diagram with general gates and its application to system reliability analysis. Annals of Nuclear Energy 2011; 38(11): 2456-2461, https://doi.org/10.1016/j.anucene.2011.07.013.

22. Marquez D, Neil M, Fenton N. Improved reliability modeling using Bayesian networks and dynamic discretization. Reliability Engineering \& System Safety 2010; 95(4): 412-425, https://doi.org/10.1016/j.ress.2009.11.012.

23. Portinale L, Bobbio A. Bayesian Networks for Dependability Analysis: an Application to Digital Control Reliability. Computer Science 2013: $551-558$.

24. Portinale L, Raiteri D C, Montani S. Supporting reliability engineers in exploiting the power of Dynamic Bayesian Networks. International Journal of Approximate Reasoning 2010; 51(2): 179-195, https://doi.org/10.1016/j.ijar.2009.05.009.

25. Seo S I, Park C S, Choi S H, et al. Reliability management and assessment for the electric traction system on the Korea High-Speed Train. Proceedings of the Institution of Mechanical Engineers Part F Journal of Rail \& Rapid Transit 2010; 224(3): 179-188, https://doi. org/10.1243/09544097JRRT297.

26. Seo S I, Park C S, Han Y J, et al. Reliability assessment of traction system of Korean high speed train. Journal of the Korean society for railway $2005 ; 8(5)$ : 434-438.

27. Sierla S, Tumer I, Papakonstantinou N, et al. Early integration of safety to the mechatronic system design process by the functional failure identification and propagation framework. Mechatronics 2012; 22(2): 137-151, https://doi.org/10.1016/j.mechatronics.2012.01.003.

28. Stone R B, Wood K L. Development of a functional basis for design. Journal of Mechanical Design 2000; 122(4): 359-370, https://doi. org/10.1115/1.1289637

29. Torres-Toledano, Sucar L E. Bayesian Networks for Reliability Analysis of Complex Systems. Lecture Notes in Computer Science 1997; 1484(1484): 465-465.

30. Wang S, Ji Y, Dong W. Reliability Analysis for High-Speed Train Control System by Means of Stochastic Automata. Advanced Science Letters 2012; 6(1): 619-624, https://doi.org/10.1166/asl.2012.2248.

31. Weber P, Jouffe L. Complex system reliability modelling with dynamic object oriented Bayesian networks (DOOBN). Reliability Engineering \& System Safety 2006; 91(2): 149-162, https://doi.org/10.1016/j.ress.2005.03.006.

32. Weber P, Medina-Oliva G, Simon C, et al. Overview on Bayesian networks applications for dependability, risk analysis and maintenance areas. Engineering Applications of Artificial Intelligence 2012; 25(4): 671-682, https://doi.org/10.1016/j.engappai.2010.06.002.

33. Wu X, Liu H, Zhang L, et al. A dynamic Bayesian network based approach to safety decision support in tunnel construction. Reliability Engineering \& System Safety 2015; 134: 157-168, https://doi.org/10.1016/j.ress.2014.10.021.

34. Y. Tian, Research on extreme small sample reliability evaluation method and its application on center sill and body bolster of C70 gondola car, Beijing: Beijing Jiaotong University, 2008.

35. Zhu D, Liu H. Reliability evaluation of high-speed train bearing with minimum sample. Journal of Central South University, 2013.

\section{Yanhui WANG}

State Key Laboratory of Rail Traffic Control and Safety Beijing Jiaotong University 100044, China

School of Traffic and Transportation

Beijing Jiaotong University, Beijing 100044, China

\section{Lifeng BI}

State Key Laboratory of Rail Traffic Control and Safety Beijing Jiaotong University 100044, China

Jinan Locomotive Depot

Jinan Railway Bureau 250001, China

\section{Shujun WANG \\ Shuai LIN \\ Wanxiao XIANG}

State Key Laboratory of Rail Traffic Control and Safety Beijing Jiaotong University 100044, China

School of Traffic and Transportation

Beijing Jiaotong University, Beijing 100044, China

E-mails: wangyanhui@bjtu.edu.cn, 1028314098@ qq.com, 14120954@bjtu.edu.cn, 13114253@ bjtu.edu.cn, 15120778@bjtu.edu.cn 